\title{
Morphological and functional changes in a new animal model of Ménière's disease
}

\author{
Naoya Egami ${ }^{1}$, Akinobu Kakigi ${ }^{1}$, Takashi Sakamoto ${ }^{1}$, Taizo Takeda ${ }^{2}$, Masamitsu Hyodo ${ }^{2}$ and Tatsuya Yamasoba ${ }^{1}$
}

The purpose of this study was to clarify the underlying mechanism of vertiginous attacks in Ménière's disease (MD) while obtaining insight into water homeostasis in the inner ear using a new animal model. We conducted both histopathological and functional assessment of the vestibular system in the guinea-pig. In the first experiment, all animals were maintained 1 or 4 weeks after electrocauterization of the endolymphatic sac of the left ear and were given either saline or desmopressin (vasopressin type 2 receptor agonist). The temporal bones from both ears were harvested and the extent of endolymphatic hydrops was quantitatively assessed. In the second experiment, either 1 or 4 weeks after surgery, animals were assessed for balance disorders and nystagmus after the administration of saline or desmopressin. In the first experiment, the proportion of endolymphatic space in the cochlea and the saccule was significantly greater in ears that survived for 4 weeks after surgery and were given desmopressin compared with other groups. In the second experiment, all animals that underwent surgery and were given desmopressin showed spontaneous nystagmus and balance disorder, whereas all animals that had surgery but without desmopressin administration were asymptomatic. Our animal model induced severe endolymphatic hydrops in the cochlea and the saccule, and showed episodes of balance disorder along with spontaneous nystagmus. These findings suggest that administration of desmopressin can exacerbate endolymphatic hydrops because of acute V2 (vasopressin type 2 receptor)-mediated effects, and, when combined with endolymphathic sac dysfunction, can cause temporary vestibular abnormalities that are similar to the vertiginous attacks in patients with MD.

Laboratory Investigation (2013) 93, 1001-1011; doi:10.1038/labinvest.2013.91; published online 22 July 2013

KEYWORDS: animal model; aquaporin; desmopressin; endolymphatic hydrops; Ménière's disease; vasopressin; vestibular disorder

Ménière's disease (MD) is a well-known inner ear disorder characterized by symptoms including recurring attacks of vertigo typically lasting for hours, fluctuating sensorineural hearing loss, and tinnitus. Since the milestone findings on the temporal bones of MD patients, ${ }^{1,2}$ endolymphatic hydrops $(\mathrm{EH})$ has been considered as the histopathological origin of $\mathrm{MD}$, as characteristic morphological changes were reported to be produced by surgical obstruction of the endolymphatic sac (ES) in guinea-pig. ${ }^{3}$ This observation indicates that malabsorption of endolymph in the ES is one of the possible mechanisms underlying the development of EH. This experimentally induced $\mathrm{EH}$ has been frequently used as an animal model to investigate the pathogenesis of inner ear disorders associated with $\mathrm{EH}$. In terms of vestibular function, while canal dysfunction and/or spontaneous nystagmus have been occasionally observed in this animal model, ${ }^{4,5}$ episodes of vertiginous attack or balance disorder have only rarely been observed. ${ }^{6}$ In other words, this model is insufficient for fully representing the common symptoms of MD.

Water homeostasis of the inner ear is essential for maintaining the functions of hearing and balance. EH is considered to be the result of disruption of inner ear water homeostasis, which involves excessive production of endolymph and/or reduced absorption of endolymph. Until recently, however, the detailed mechanisms underlying the overaccumulation of endolymph were unclear. Since the discovery of aquaporin (AQP) water channels, ${ }^{7}$ it has been proposed that precise regulation of water reabsorption largely depends on the regulation of AQP2 channels and that water permeability can change rapidly in response to vasopressin(VP). ${ }^{8}$ Recently, it has come to light that this mechanism has a crucial role not only in the kidney but also in the inner ear. In addition, the following evidence has accumulated to suggest that VP is closely associated with the

\footnotetext{
${ }^{1}$ Department of Otolaryngology-Head and Neck Surgery, Faculty of Medicine, The University of Tokyo, Tokyo, Japan and ${ }^{2}$ Department of Otolaryngology-Head and Neck Surgery, Kochi Medical School, Kochi, Japan

Correspondence: Dr A Kakigi, MD, Department of Otolaryngology, Faculty of Medicine, The University of Tokyo, 7-3-1 Hongo, Bunkyo-ku, Tokyo 113 8655, Japan. E-mail: kakigi-tky@umin.ac.jp

Received 30 April 2013; revised 20 June 2013; accepted 22 June 2013
} 
formation of EH: (1) plasma levels of arginine VP are higher in patients with MD and may depend on the phase that the patient is in, ${ }^{9-11}(2)$ acute and chronic application of arginine VP produces EH in guinea-pigs and rats, ${ }^{12-14}$ (3) V2 receptor mRNA is expressed in rat and human inner ear, ${ }^{15-18}$ and (4) expression of V2 receptor mRNA in the rat inner ear is downregulated by VP application. ${ }^{19}$ Such accumulated evidence has led to the assumption that production of endolymph is controlled by VP-AQP2 system.

In a previous study using an animal model of $\mathrm{MD}$, Dunnebier $e t a l^{20}$ reported chronic ES dysfunction induced by destruction of the ES, and acute stress-induced endolymph production by aldosterone administration revealed severe degrees of hydrops in the cochlea. ${ }^{20}$ In this investigation, we successfully developed a new clinically relevant animal model for $\mathrm{MD}$, in which desmopressin (a VP type 2 receptor agonist) was administered after electrocauterization of the ES.

We evaluated both morphological and behavioral alterations of the vestibular system in this animal model to elucidate the role of VP in the pathogenesis of MD.

\section{MATERIALS AND METHODS}

This study was composed of two experiments. Experiment 1 was designed to investigate the influence of desmopressin on the development of EH morphologically. Experiment 2 was designed to investigate the role of desmopressin on changes in vestibular function. The animals used in Experiment 1 were albino outbred English short-haired guinea-pig (Hartley). In Experiment 2, pigmented English short-haired guinea-pig were used. Pigmented animals were selected for Experiment 2 to facilitate eye movement recording using an infrared-sensitive CCD camera.

These experiments were approved by Tokyo University Animal Care and Use Committee, and were conducted in accordance with The Animal Welfare Act and the guiding principles for animal care produced by the Ministry of Education, Culture, Sports, and Technology, Japan.

\section{Experiment 1}

\section{Animals}

A total of 24 guinea-pigs with a positive Preyer's reflex and weighing approximately $300 \mathrm{~g}$ were used in this experiment. All animals underwent electrocauterization of the ES of the left ear as reported previously. ${ }^{21,22}$ The right ear was not treated surgically. The surgical procedures are described below (in the Surgical procedure for electrocauterization of the ES section). Animals were divided into two major groups. Twelve animals were allocated to survive for 1 week after electrocauterization of the ES and the other 12 for 4 weeks. In either group, six animals were given saline and the remaining six were treated with desmopressin systemically $1 \mathrm{~h}$ before euthanasia. In animals treated with desmopressin, $100 \mu \mathrm{g} / \mathrm{kg}(25 \mathrm{ml} / \mathrm{kg})$ desmopressin acetate hydrate (desmopressin 4; Kyowa Hakko Kirin, Tokyo, Japan) was administered subcutaneously $1 \mathrm{~h}$ before euthanasia. In saline-treated animals, $25 \mathrm{ml} / \mathrm{kg}$ saline solution was administered subcutaneously $1 \mathrm{~h}$ before euthanasia. All animals were killed under deep anesthesia using ketamine and xylazine, and the temporal bones were collected from both sides. As shown in Figure 1a, 48 temporal bones harvested were classified into eight groups $(n=6)$ according to the presence or absence of surgery, the survival duration, and type of treatment: (1) right temporal bones, 1-week survival after left ear electrocauterization, administered saline (1 W Control group (RIGHT)); (2) left temporal bones of the above-mentioned animals (1 W Surgery group (LEFT)); (3) right temporal bones, 1-week survival after left ear electrocauterization, administered desmopressin ( $1 \mathrm{~W}$ Desmopressin group (RIGHT)); (4) left temporal bones of the above-mentioned animals (1 W Combined group (LEFT)); (5) right temporal bones, 4-week survival after left ear electrocauterization, administered saline $(4 \mathrm{~W}$ Control group (RIGHT)); (6) left temporal bones of the above-mentioned animals (4W Surgery group (LEFT)); (7) right temporal bones, 4-week survival after left ear electrocauterization, administered desmopressin $(4 \mathrm{~W}$ Desmopressin group (RIGHT)), and (8) left temporal bones of the abovementioned animals (4 W Combined group (LEFT)).

\section{Surgical procedure for Electrocauterization of the ES}

All experimental animals were anesthetized by an intramuscular injection of ketamine $(35 \mathrm{mg} / \mathrm{kg})$ and xylazine $(5 \mathrm{mg} / \mathrm{kg})$. The animals received local anesthesia using xylocaine under sterile conditions. Subsequently, they were placed in a prone position with a head holder and underwent dorsal midline scalp incision. The left occipital bone was removed for visual exposure of the ES via an epidural occipital approach. Thereafter, the extraosseous portion of the sac was cauterized electrically with a bipolar electrocoagulator (Surgitron Model FFPF; Ellman International, Hewlett, NY, USA) so as not to injure the sigmoid sinus. The operation was performed using a Carl Zeiss operation microscope.

\section{Quantitative Assessment of the Endolymphatic Space}

Under deep anesthesia by an intraperitoneal injection of ketamine $(35 \mathrm{mg} / \mathrm{kg})$ and xylazine $(5 \mathrm{mg} / \mathrm{kg})$, all animals were perfused from the left ventricle with physiological saline solution, and then fixed with $10 \%$ formalin. The temporal bones were removed on both sides and postfixed in $10 \%$ formalin solution for 7 days. Subsequently, the specimens were decalcified in ethylenediamine tetraacetic acid for 14 days, and then dehydrated in a graded ethanol series before being embedded in paraffin. The prepared blocks were cut horizontally parallel to the axis of the modiolus into $6-\mu \mathrm{m}$ sections. The sections were stained with hematoxylin and eosin for observation under a light microscope. We examined the degree of $\mathrm{EH}$ in the cochleae, vestibules, and semicircular canals using digital image measurement software, Micro Analyzer Ver. 1.1 (Nippon Poladigital, Tokyo, Japan). 


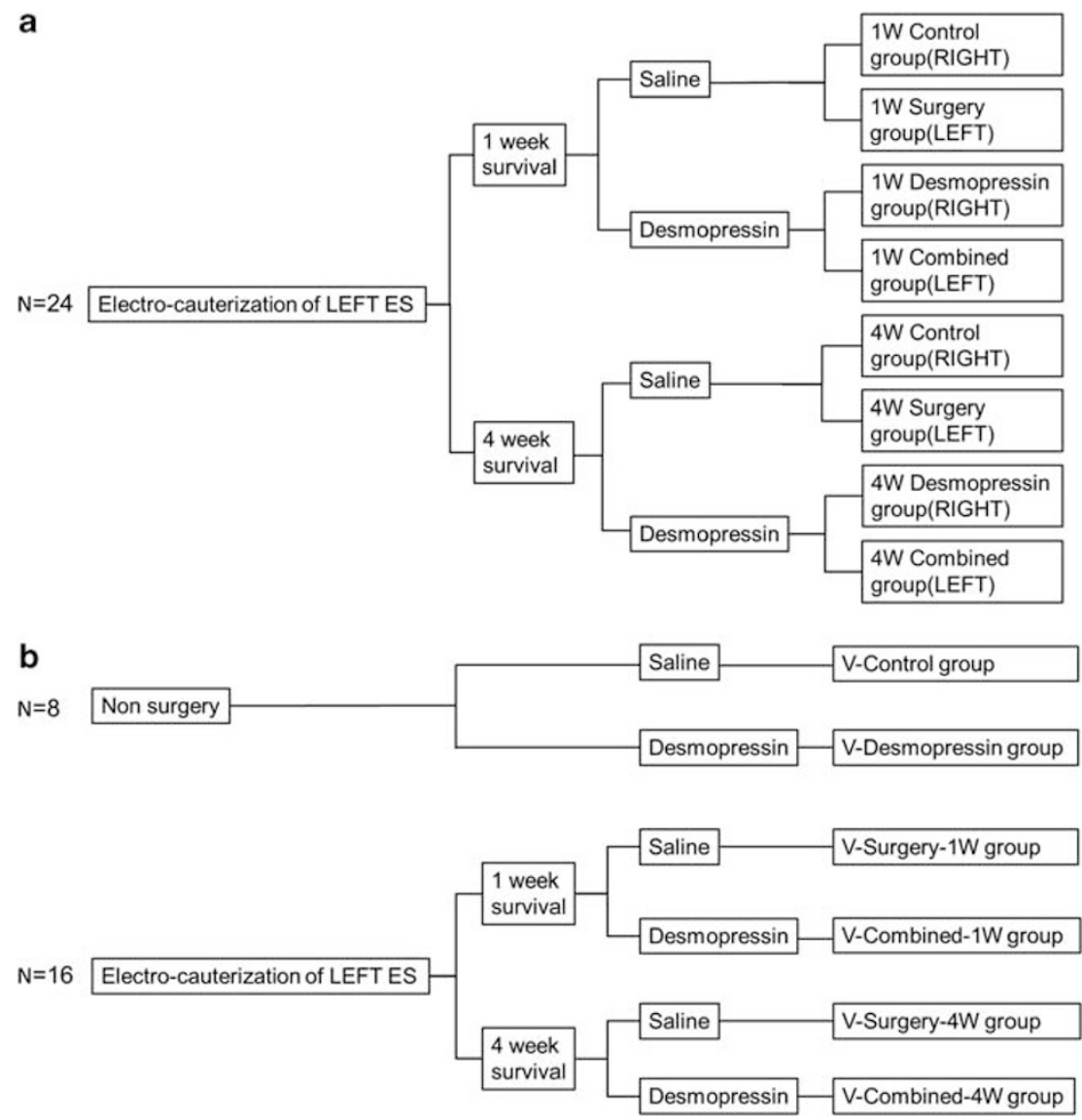

Figure 1 (a) Flow diagram of the experimental animals in Experiment 1. All animals underwent electrocauterization of the endolymphatic sac (ES) and duct on the left side and were randomly divided into two groups of either 1 or 4 weeks survival. The right ear of the saline administration group represents the 'Control group', and the left ear the 'Surgery group'. The right ear of the desmopressin administration group represents the 'Desmopressin group', and the left ear the 'Combined group'. (b) The study design of Experiment 2: (1) V-Control group; (2) V-Desmopressin group: animals without any surgical procedure, and with saline or desmopressin treatment $1 \mathrm{~h}$ before vestibular examination; (3) V-Surgery- $1 \mathrm{~W}$ group; (4) $V$-Combined-1 $W$ group: animals with electrocauterization of the ES after 1 week survival, and saline or desmopressin treatment $1 \mathrm{~h}$ before vestibular examination; (5) V-Surgery-4 W group; and (6) V-Combined-4 W group: animals with electrocauterization of the ES after 4 weeks survival, and saline or desmopressin treatment $1 \mathrm{~h}$ before vestibular examination.

To assess quantitatively the endolymphatic space variations across the cochlea turns, we measured the increase in the ratio of the cross-sectional area of the scala media (IR-S) in the basal, second, third, and apical turns, excluding the hook portion at the mid-modiolar sections. For this analysis, we used the following two parameters: (1) the cross-sectional area of the dilated scala media (Figure 2a, gray area), and (2) the cross-sectional area of the original scala media, enclosed by a straight line segment (Figure 2a, black area). This line segment represents the normal position of Reissner's membrane at the upper margin of the stria vascularis and its normal medial attachment at the spiral limbus. From these parameters, we calculated the increased ratios (\%) of the cross-sectional area of the scala media (IR-S) of a total of four turns using the following formula:

Total IR-S $(\%)=100 \times\left(\sum(A x-B x) / x B x\right)(x$ : basal second, third, apical turn)

For the quantitative assessment of the spread of the endolymphatic space of the saccule, we measured the proportion of the area of the saccule (Figure 2b, gray area) relative to that of the vestibule (Figure 2b, black area) in the horizontal section including the stapes footplate. In the utricle, we also examined the proportion of the area of the utricle (Figure 2c, gray area) to that of the labyrinth (Figure 2c, black area) in the horizontal section including the crista of the lateral semicircular canal. For the semicircular canal, we examined the area of endolymph of the posterior semicircular canal (Figure 2d, gray area) relative to the area of bony posterior semicircular canal (Figure 2d, black area) in the horizontal section including the crista of the posterior semicircular canal.

\section{Statistical Analyses}

Differences in the degree of endolymph space by surgical procedure were evaluated for individual subjects by paired $t$-test. We compare the differences in the mean values among each group with Tukey's multiple comparison test. StatMate IV (ATMS, Tokyo, Japan) was used to conduct these analyses. 
The data are presented as mean \pm s.d., unless otherwise noted. A difference of $P<0.05$ was considered significant.

\section{Experiment 2 \\ Animals}

A total of 24 pigmented guinea-pigs with a positive Preyer's reflex weighing approximately $300 \mathrm{~g}$ were used. Sixteen animals underwent electrocauterization of the ES in the left ear, and the remaining eight animals received no surgical procedure. The 16 animals that underwent surgery were divided into two groups, which were maintained for 1 week or 4 weeks before administration of saline or desmopressin. In either group, four animals were given saline and the remaining four animals were given desmopressin. Saline and desmopressin treatments were performed in the same manner as in Experiment 1. Animals that underwent surgery were assessed for evidence of a balance disorder and the presence of nystagmus for $1 \mathrm{~h}$ after they received a subcutaneous injection of $25 \mathrm{ml} / \mathrm{kg}$ saline solution, or $100 \mu \mathrm{g} / \mathrm{kg}$ $(25 \mathrm{ml} / \mathrm{kg})$ desmopressin acetate hydrate. Similarly in the eight surgery-free animals, vestibular examinations were undertaken for $1 \mathrm{~h}$ after administration of saline or desmopressin.

As shown in Figure 1b, experimental animals were classified into six groups $(n=4)$ according to the presence or absence of surgery, the survival duration, and type of treatment: (1) V-Control group: surgery-free animals administered saline; (2) V-Desmopressin group: surgery-free animals administered desmopressin; (3) V-Surgery-1 W group: animals given saline 1 week after electrocauterization of the ES; (4) V-Combined-1 $\mathrm{W}$ group: animals given desmopressin 1 week after electrocauterization of the ES; (5) V-Surgery- $4 \mathrm{~W}$ group: animals given saline 4 weeks after electrocauterization of the ES; and (6) V-Combined-4 W group: animals given desmopressin 4 weeks after electrocauterization of the ES.

\section{Vestibular Examinations}

We recorded spontaneous nystagmus with an eye movement recording system in a dark room for $1 \mathrm{~h}$ after administration of saline or desmopressin. The maximum slow-phase velocity was measured. The recording procedure has been described previously. ${ }^{5}$ The dark iris can be detected using an infrared-
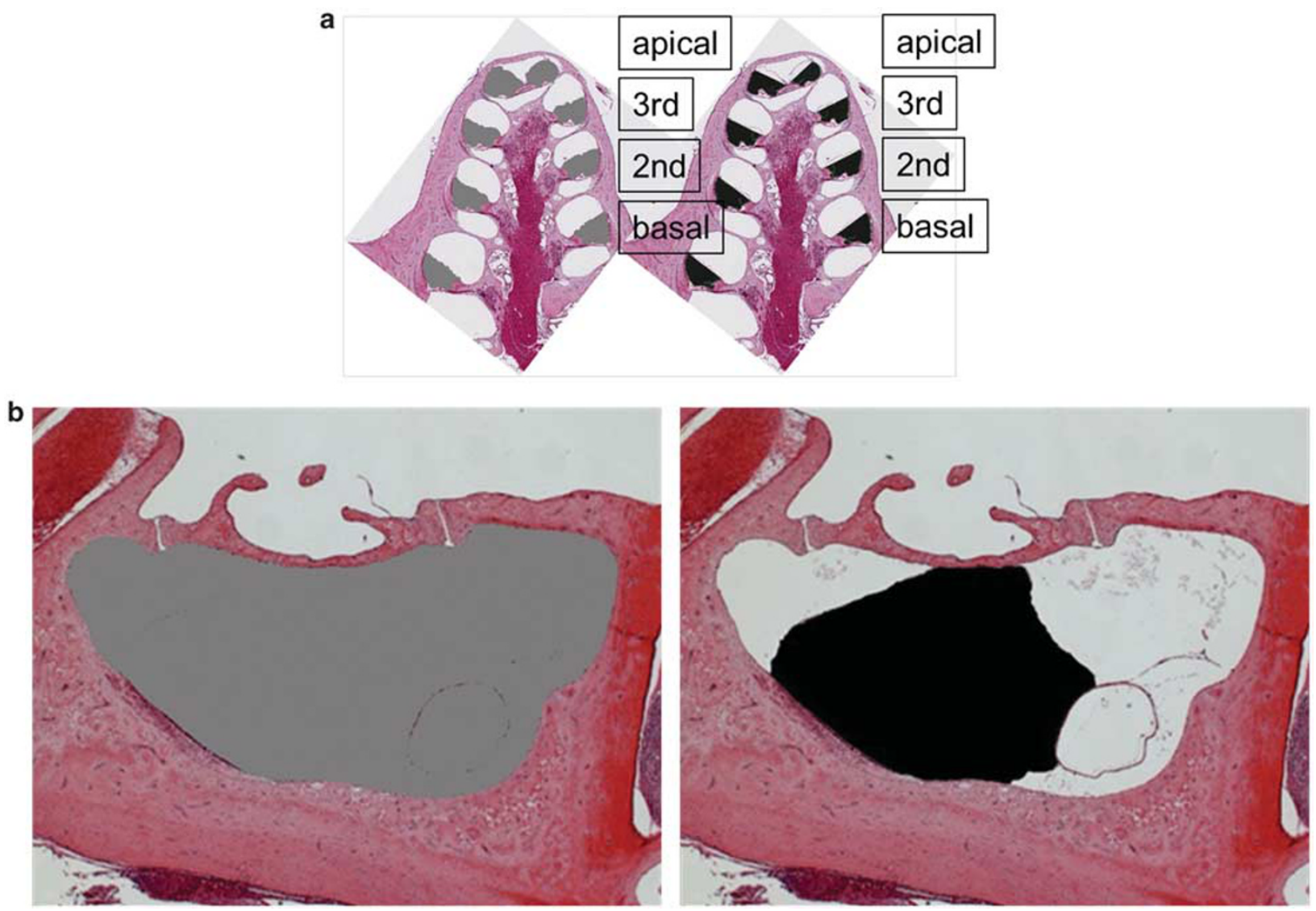

Figure 2 Parameters for the quantitative assessment of changes in the endolymphatic space. (a) The cross-sectional areas of the basal, 2 nd, 3rd, and apical turns are indicated for the non-bulging scala media (gray, left) and the bulging scala media (black, right). (b) The vestibule (gray area, left) and the saccule (black area, right) in a horizontal section including the stapes footplate. (c) The labyrinth (gray area, left) and the utricle (black area, right) in a horizontal section including the crista of the lateral semicircular canal. (d) The bony posterior semicircular canal (gray area, left) and the endolymph of the posterior semicircular canal (black area, right) in a horizontal section including the crista of the posterior semicircular canal. 
c

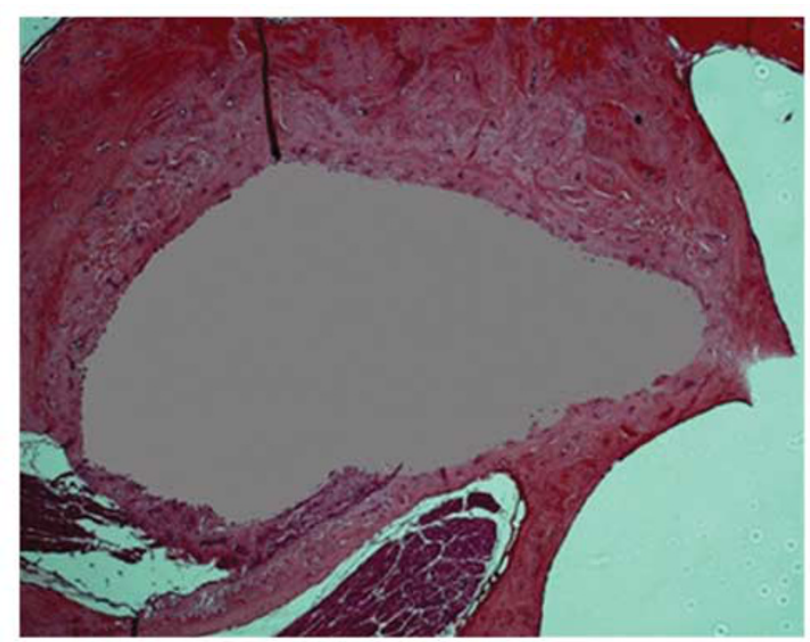

d

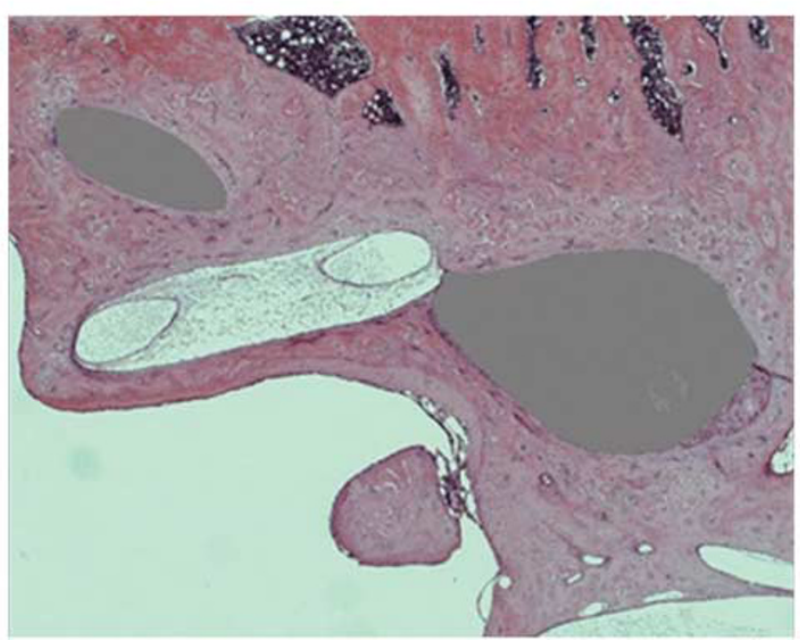

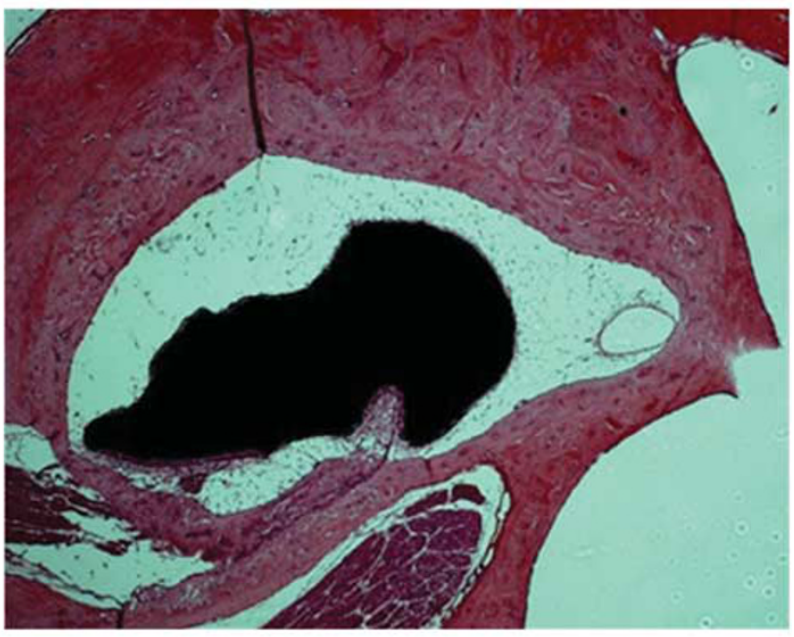

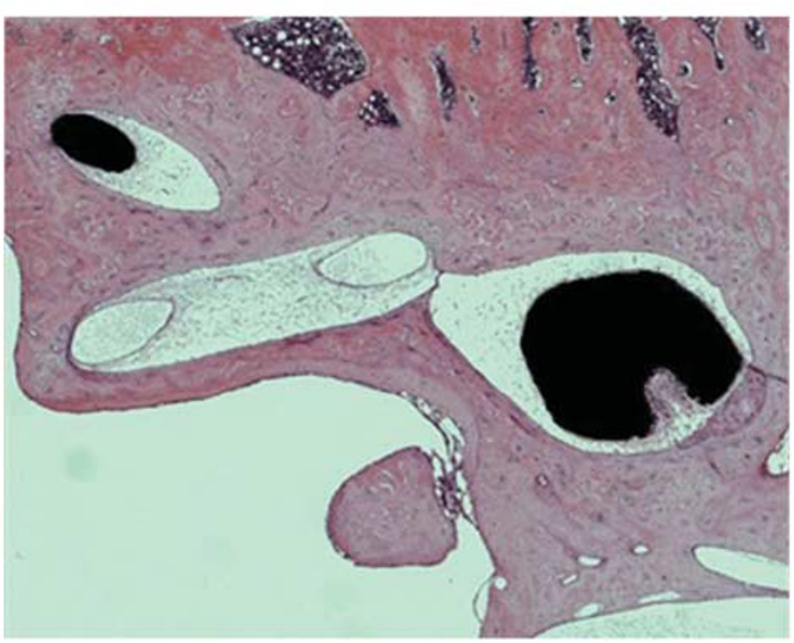

Figure 2 (Continued)

sensitive CCD camera to produce a binary image; the eye position and velocity are then calculated by a personal computer. We also monitored posture for $1 \mathrm{~h}$ after the administration of saline or desmopressin to determine the presence or absence of a balance disorder. Postural disturbances during a vestibular attack were videotaped.

\section{RESULTS}

\section{Experiment 1}

Figures 3 and 4 show representative pictures of the cochlea and the saccule in the four following groups: $4 \mathrm{~W}$ Control group, $4 \mathrm{~W}$ Surgery group, $4 \mathrm{~W}$ Desmopressin group, and $4 \mathrm{~W}$ Combined group. Reissner's membrane was almost straight in the $4 \mathrm{~W}$ Control group and $4 \mathrm{~W}$ Desmopressin group (Figures $3 \mathrm{a}$ and $\mathrm{c}$ ), whereas it was moderately extended in the $4 \mathrm{~W}$ Surgery group (Figure $3 \mathrm{~b}$ ), and bulged into the scala vestibuli in the $4 \mathrm{~W}$ Combined group (Figure 3d). Saccular hydrops was not observed in the $4 \mathrm{~W}$ Control group or the $4 \mathrm{~W}$ Desmopressin group (Figures $4 \mathrm{a}$ and c), whereas the saccular space was moderately extended in the $4 \mathrm{~W}$ Surgery group (Figure $4 \mathrm{~b}$ ). In the $4 \mathrm{~W}$ Combined group, the saccular space was markedly extended and the saccular membrane was widely adhered to the stapes footplate (Figure 4d). There was no significant hydrops in the utricle or semicircular canal in any group, except that one animal in $4 \mathrm{~W}$ Combined group showed a slight expansion of the utricular space.

Figure 5 shows the results of quantitative analyses of the changes in the endolymphatic space in the cochlea, saccule, utricle, and the semicircular canal. In the cochlea, total IR-S (\%) in the $1 \mathrm{~W}$ or $4 \mathrm{~W}$ Combined group showed a significantly greater ratio compared with the $1 \mathrm{~W}$ or $4 \mathrm{~W}$ Desmopressin group (paired $t$-test, $P<0.05$ and $P<0.01$, respectively; Figure $5 \mathrm{a}$ ). In the $4 \mathrm{~W}$ Surgery group, the IR-S was significantly greater than that of the $4 \mathrm{~W}$ Control group (paired $t$-test, $P<0.05$; Figure $5 \mathrm{a}$ ); however, the IR-S was not significantly different between $1 \mathrm{~W}$ Control group and $1 \mathrm{~W}$ Surgery group (paired $t$-test, $P>0.05$; Figure $5 \mathrm{a}$ ). Total IR-S (\%) in the $4 \mathrm{~W}$ Combined group was significantly greater when compared with the $1 \mathrm{~W}$ Surgery group, $1 \mathrm{~W}$ Combined group, and $4 \mathrm{~W}$ Surgery group (Tukey's multiple comparison test, $P<0.001$; Figure 5a). There were no significant 
a

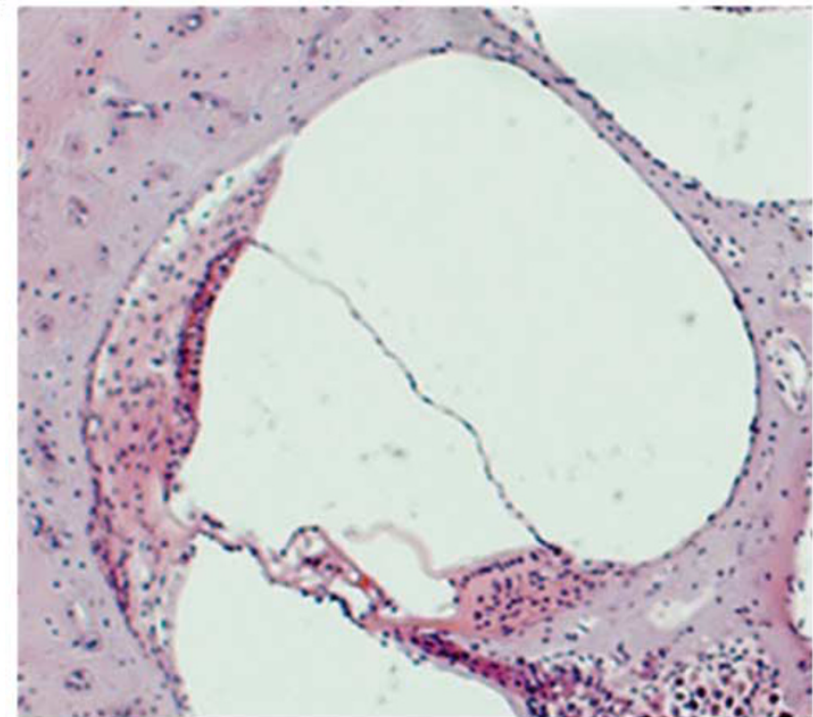

c

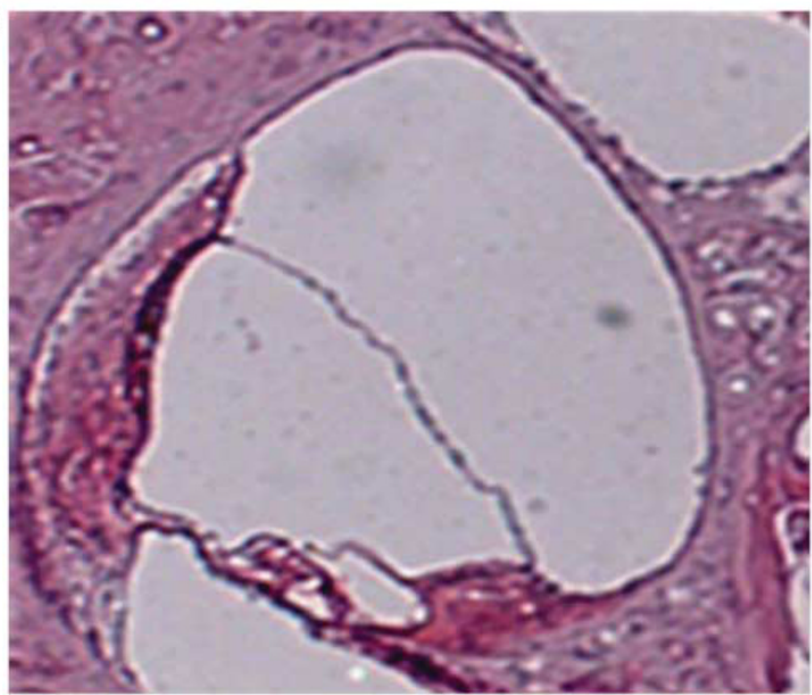

b

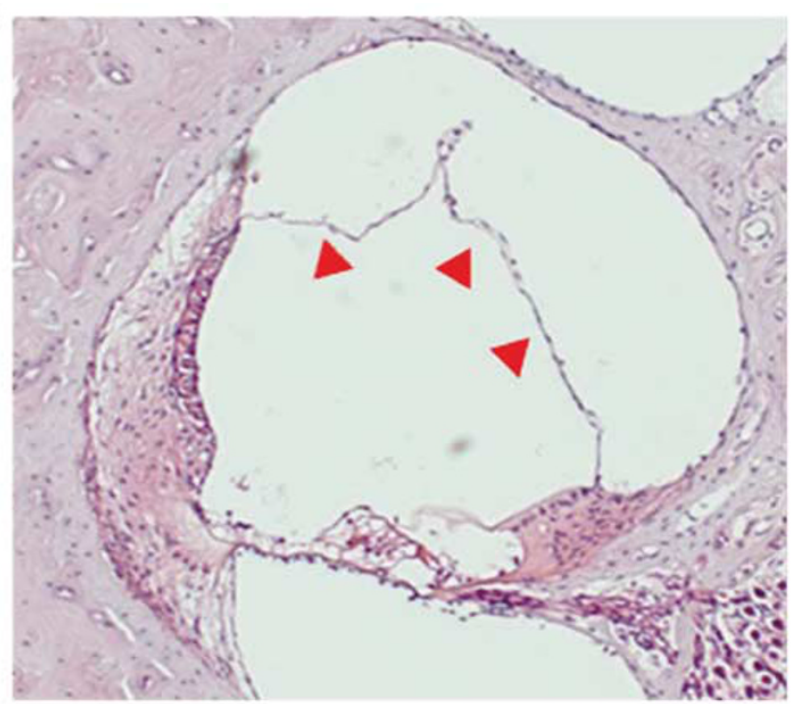

d

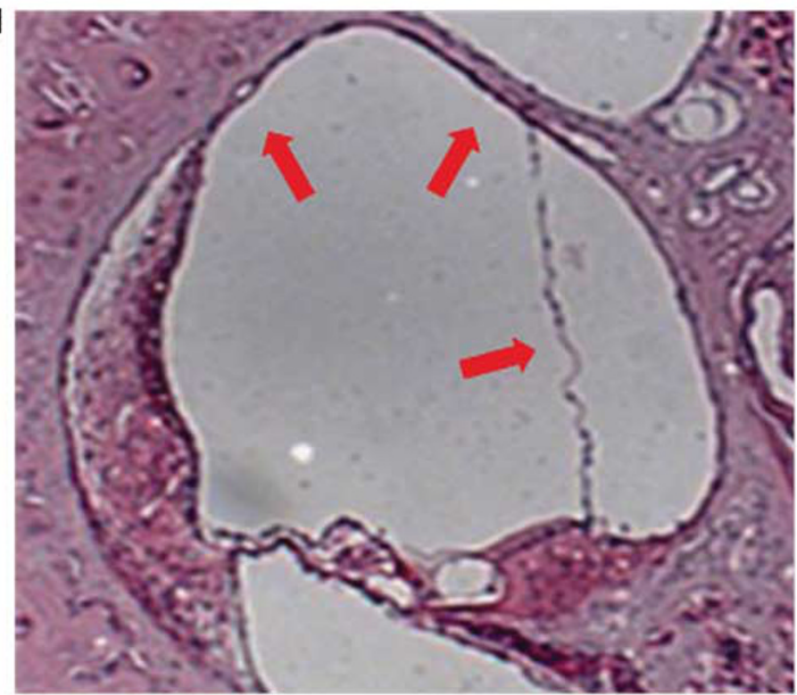

Figure 3 Representative pictures of the cochlea in the four ear groups maintained for 4 weeks: (a) saline-infused Control ear, (b) saline-infused Surgery ear, (c) desmopressin-infused Desmopressin ear, and (d) Combined ear. In the Surgery ear group, the scala media is distended and shows moderate hydrops (arrowhead). In the Combined ear, Reissner's membrane is bulging into the scala vestibule, which exhibits severe endolymphatic hydrops (arrow).

differences among $1 \mathrm{~W}$ and $4 \mathrm{~W}$ Control groups and $1 \mathrm{~W}$ and $4 \mathrm{~W}$ Desmopressin groups (Tukey's multiple comparison test, $P>0.05$; Figure 5a). Total IR-S (\%) was significantly greater in the $4 \mathrm{~W}$ Combined group than in the $4 \mathrm{~W}$ Surgery group, and also in the $1 \mathrm{~W}$ Combined group than in the $1 \mathrm{~W}$ Surgery group ( $t$-test, $P<0.05$; Figure 5a).

We also estimated the progression of cochlea $\mathrm{EH}$ in the Surgery and Combined groups. In the Surgery group, EH appeared to gradually develop over a time scale of weeks. The average growth rates of $\mathrm{EH}$ development in the Surgery group were estimated from the IR data in the $1 \mathrm{~W}$ or $4 \mathrm{~W}$ groups using the following formula: (IR-S (\%) of the $1 \mathrm{~W}$ or $4 \mathrm{~W}$ Surgery groups - IR-S (\%) of the $1 \mathrm{~W}$ or $4 \mathrm{~W}$ Control groups $) / 168 \mathrm{~h}(1 \mathrm{~W})$ or $672 \mathrm{~h}(4 \mathrm{~W})$. The average growth rates of $\mathrm{EH}$ development were $0.008 \% / \mathrm{h}$ in the $1 \mathrm{~W}$ group and $0.025 \% / \mathrm{h}$ in the $4 \mathrm{~W}$ group. In the Combined group, $\mathrm{EH}$ appeared to develop within $1 \mathrm{~h}$ of desmopressin administration. The average growth rates of $\mathrm{EH}$ development were estimated from the IR data using the following formula: IR-S (\%) of the $1 \mathrm{~W}$ or $4 \mathrm{~W}$ Combined group - IR-S (\%) of the $1 \mathrm{~W}$ or $4 \mathrm{~W}$ Surgical group. The average growth rates of $\mathrm{EH}$ development were $27.2-14.7 \%=12.5 \% / \mathrm{h}$ and $60.0-36.3 \%=23.7 \% / \mathrm{h}$ for the $1 \mathrm{~W}$ and $4 \mathrm{~W}$ groups, respectively.

The proportion of the saccular space was greater in the $1 \mathrm{~W}$ Combined group compared with the $1 \mathrm{~W}$ Desmopressin group (paired $t$-test, $P<0.05$; Figure $5 \mathrm{~b}$ ) and in the $4 \mathrm{~W}$ Combined group compared with the $4 \mathrm{~W}$ Desmopressin group (paired $t$-test, $P<0.001$; Figure $5 \mathrm{~b}$ ). In the $1 \mathrm{~W}$ and $4 \mathrm{~W}$ Surgery groups, the proportion of the saccular space was 

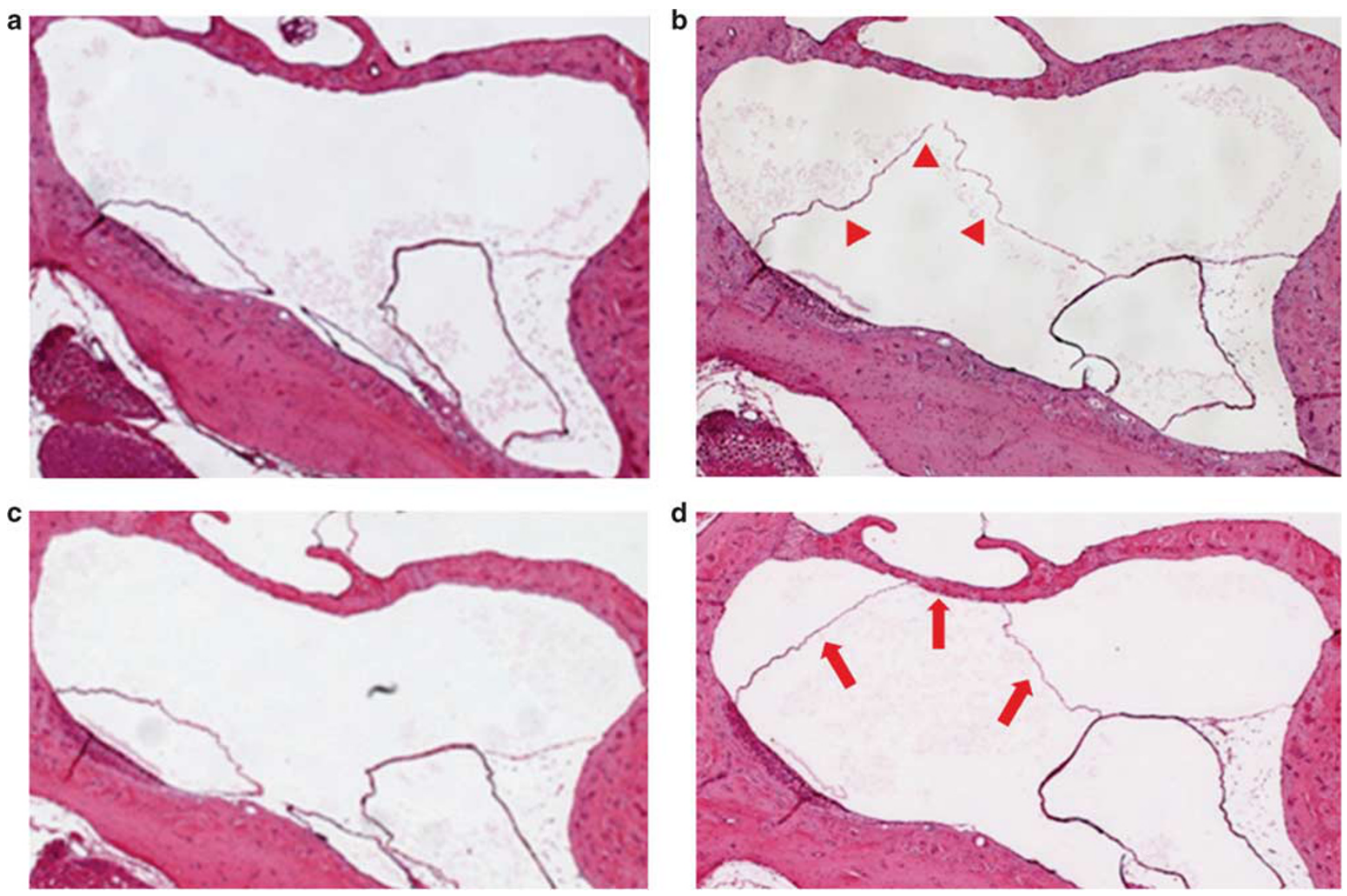

Figure 4 Representative pictures of the saccule in the four ear groups maintained for 4 weeks: (a) saline-infused Control ear, (b) saline-infused Surgery ear, (c) desmopressin-infused Desmopressin ear, and (d) Combined ear. In the Surgery ear group, moderate saccular hydrops can be seen (arrowhead). In the Combined ear group, severe saccular hydrops has extended to press against the stapes footplate (arrow).

significantly greater compared with the $1 \mathrm{~W}$ and $4 \mathrm{~W}$ Control groups (paired $t$-test, $P<0.05$ in both comparisons; Figure $5 \mathrm{~b}$ ). The proportion of the saccular space in the $4 \mathrm{~W}$ Combined group was significantly greater when compared with the $1 \mathrm{~W}$ Surgery group, $1 \mathrm{~W}$ Combined group, and $4 \mathrm{~W}$ Surgery group (Tukey's multiple comparison test, $P<0.001$; Figure $5 \mathrm{~b})$. There were no significant differences among the $1 \mathrm{~W}$ and $4 \mathrm{~W}$ Control groups and $1 \mathrm{~W}$ and $4 \mathrm{~W}$ Desmopressin groups (Tukey's multiple comparison test, $P>0.05$; Figure $5 \mathrm{~b}$ ). The proportion of the saccular space was significantly greater in the $4 \mathrm{~W}$ Combined group than in the $4 \mathrm{~W}$ Surgery group ( $t$-test, $P<0.001$; Figure $5 \mathrm{~b}$ ), and also in the $1 \mathrm{~W}$ Combined group than in the $1 \mathrm{~W}$ Surgery group ( $t$-test, $P<0.05$; Figure $5 \mathrm{~b}$ ).

We also estimated the progression of saccular hydrops in the Surgery and Combined groups. In the Surgery group, saccular hydrops appeared to develop over a time scale of weeks. The average growth rates of development of saccular hydrops was estimated from the proportion of saccular space remaining using the following formula for both the $1 \mathrm{~W}$ and $4 \mathrm{~W}$ groups: (proportion remaining (\%) in the $1 \mathrm{~W}$ or $4 \mathrm{~W}$ Surgery group - proportion remaining (\%) in the $1 \mathrm{~W}$ or $4 \mathrm{~W}$ Control group $) / 168 \mathrm{~h}(1 \mathrm{~W})$ or $672 \mathrm{~h}(4 \mathrm{~W})$. The average growth rates of development of saccular hydrops were
$0.03 \% / \mathrm{h}$ and $0.02 \% / \mathrm{h}$ for the $1 \mathrm{~W}$ and $4 \mathrm{~W}$ groups, respectively. Comparing growth rates of development of saccular hydrops in the Surgery and Combined groups in the same manner yielded average speeds of $25.2-12.7 \%=12.5 \% / \mathrm{h}$ for the $1 \mathrm{~W}$ group and $51.9-24.6 \%=27.3 \% / \mathrm{h}$ for the combined group.

In the utricle, there were no significant differences among the four groups maintained for either 1 week or 4 weeks (Figure 5c). In both the semicircular canal ampulla and the duct, there were also no significant differences among the four groups maintained for either 1 week or 4 weeks (Figures 5d and e).

\section{Experiment 2}

All of animals in the V-Combined- $1 \mathrm{~W}$ and V-Combined- $4 \mathrm{~W}$ groups showed spontaneous nystagmus (Table 1 and Supplementary Movie 1 in Supplementary Material) and balance disorder (Supplementary Movie 2 in Supplementary Material). After the administration of desmopressin, one animal in the V-Desmopressin group demonstrated spontaneous nystagmus. No animals in the V-Control group, V-Surgery-1 W, and V-Surgery-4 W groups showed any nystagmus. Table 2 shows the maximum slow-phase velocity in the animals in the V-Combined-1 W and V-Combined $-4 \mathrm{~W}$ 
a

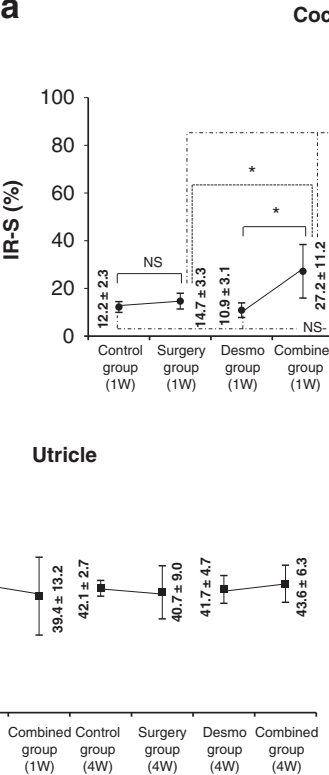

Cochlea

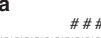

\#\#\#

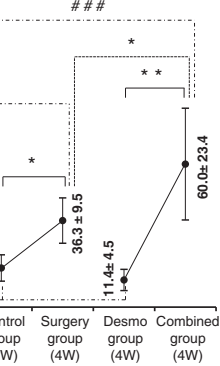

b

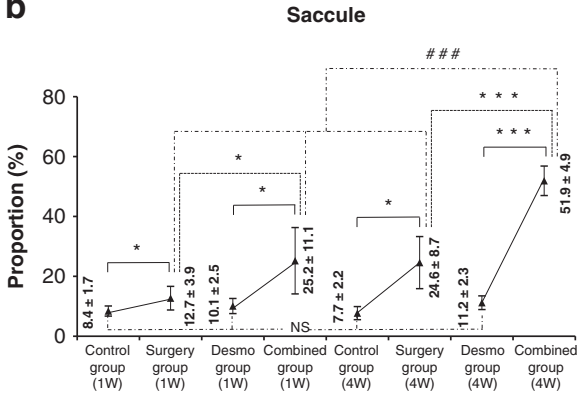

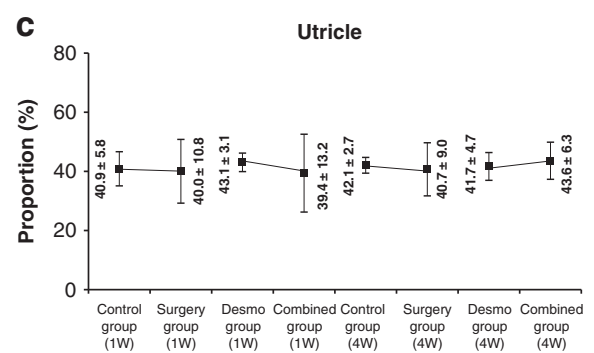
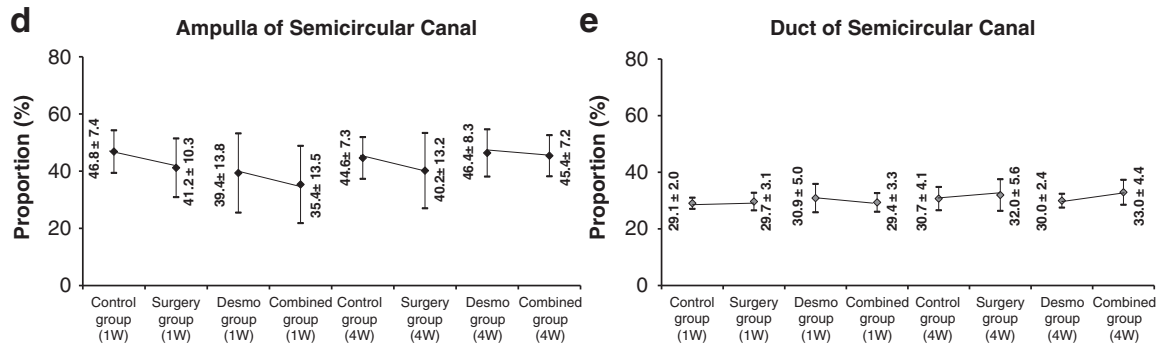

Figure 5 Result of quantitative analyses of the changes in endolymphatic space. (a) In the cochlea, total IR-S (\%) in the Combined group maintained for 4 weeks showed a significant increase among four groups (paired $t$-test, ${ }^{*} P<0.05,{ }^{* *} P<0.01 ; t$-test, ${ }^{*} P<0.05$; Tukey's multiple comparison test, $\left.\# \#{ }^{\#}<0.001\right)$. (b) The proportion of the area of the saccule to that of the vestibule showed a significant increase in the Combined group maintained for 4 weeks (paired $t$-test, ${ }^{*} P<0.05,{ }^{* * *} P<0.001$; $t$-test, ${ }^{*} P<0.05,{ }^{* * *} P<0.001$; Tukey's multiple comparison test, ${ }^{\# \# \#} P<0.001$ ). (c) The proportion of the area of the utricle to that of the vestibule showed no differences among either ear group or period of maintenance, 1 or 4 weeks. (d, e) In addition, the proportion of the area of the semicircular canal ampulla and duct to that of the vestibule showed no difference among either ear group or period of maintenance, 1 or 4 weeks.

groups, which presented spontaneous nystagmus. In cases 2 , 6 , and 7 , the direction of nystagmus changed from the left to the right, indicating a change from irritative nystagmus to paralytic nystagmus. Typically, $10 \mathrm{~min}$ after the onset of the irritative nystagmus, the direction of nystagmus changed to the paralytic.

In cases 1,5 , and 8 , only paralytic spontaneous nystagmus appeared (Supplementary Movie 1). In cases 3 and 4, only irritative spontaneous nystagmus appeared. The amplitude and direction of the maximum slow-phase velocity varied among the animals.

\section{DISCUSSION}

In this investigation, we successfully developed a new clinically relevant animal model for $\mathrm{MD}$, in which desmopressin was administered after electrocauterization of the ES. In this animal model, distinct $\mathrm{EH}$ was evident in the cochlea and saccule, whereas there were no obvious changes in the utricle or semicircular canals. Temporal bone studies of patients with $\mathrm{MD}$ have revealed that $\mathrm{EH}$ is more frequently observed in the pars inferior than in the pars superior of the inner ear. It has been shown that severe $\mathrm{EH}$ is observed most frequently in the saccule, followed by the cochlea, utricle, and the semicircular canals. ${ }^{23}$ Recent studies using magnetic resonance imaging have also confirmed these histopathologic findings. ${ }^{24,25}$ In the Surgery group in Experiment 1, ears that underwent electrocauterization of the ES but without administration of desmopressin developed slight to moderate hydrops, indicating that prolonged ES dysfunction induced by electrocauterization may cause malabsorption of endolymph, and thus development of EH. This assumption is in line with following histopathologic findings related to the ES in patients with MD: poor development of the ES, ${ }^{26,27}$ fibrotic changes of the ES, and a hypoplastic vestibular aqueduct. $^{28,29}$

Experimentally induced EH, first proposed by Kimura and Schuknecht in $1965,{ }^{3}$ is well known as an animal model of $\mathrm{MD}$. The $\mathrm{EH}$ of their model is thought to involve retention hydrops caused by the obliteration of the endolymphatic duct. This model animal is reported to have spontaneous nystagmus in the dark, ${ }^{5,6,30}$ but not in the light. ${ }^{31}$ In horizontal vestibular ocular reflex testing, vestibular ocular reflex gain was found to have decreased 1 week after the obliteration of ES. ${ }^{5}$ These experimental results suggest that $\mathrm{EH}$ might contribute to vestibular dysfunction to some extent and that vestibular dysfunction might occur during the development and/or progression of $\mathrm{EH}$. Episodes of temporary imbalance or vertigo, which are typical features of patients with MD, have not however been reported in animals that underwent obliteration of their ES. Therefore, such animals with EH due only to the retention of endolymph are not considered suitable as an animal model of MD.

Considering these issues, we speculated that the lack of temporary vestibular episodes in the classical MD animal model might be related to growth rates of formation of $\mathrm{EH}$, not the degree of $\mathrm{EH}$. That is, the development 
of EH caused by malabsorption in the ES is too slow to produce a vertiginous attack. Indeed, animals that survived for 4 weeks after electrocauterization of the left ES ( $4 \mathrm{~W}$ Surgery group) developed severe $\mathrm{EH}$ in the cochlea and the saccule, but showed no distinct vestibular disorders. Therefore, we modified the classical animal model with the additional administration of desmopressin to accelerate the development of $\mathrm{EH}$.

As expected, animals given desmopressin 1 or 4 weeks after the electrocauterization of the ES showed both spontaneous nystagmus and balance disorders (V-Combined-1 W group and V-Combined- $4 \mathrm{~W}$ group). Most of the V-Combined group animal showed desmopressin-induced vestibular disorders about $1 \mathrm{~h}$, which agrees with the time course of desmopressin-induced intrastrial space enlargement. ${ }^{32}$ Morphological changes indicated that animals that survived for 4 weeks after the electrocauterization of the left ES combined with administration of desmopressin ( $4 \mathrm{~W}$ Combined group) had severe $\mathrm{EH}$ in the cochlea and the saccule, and that the degree of $\mathrm{EH}$ was extremely high compared with animals that survived for only 1 week after electrocauterization of the left ES and the administration of desmopressin (1 W Combined group) even though both groups demonstrated episodes of vestibular dysfunction. The degree of EH and the saccular hydrops in the $1 \mathrm{~W}$ and $4 \mathrm{~W}$ combined groups was extremely high compared with animals that survived for 1 or 4 weeks after the electrocauterization of the left ES alone (1 W and $4 \mathrm{~W}$ Surgery group) (Figure $5 \mathrm{a}$ and $b$ ). Thus, the disorders of vestibular function could not be rationalized on the basis of the degree of EH. With the dynamic changes of $\mathrm{EH}$ in mind, however, another theory could be proposed. In the $1 \mathrm{~W}$ and $4 \mathrm{~W}$ Surgery groups, $\mathrm{EH}$ is thought to develop gradually over 1 and 4 weeks. On the other hand, EH in animals administered desmopressin is thought to develop as rapidly as within $1 \mathrm{~h}$. Analysis of the average growth rates of $\mathrm{EH}$ development, estimated from the IR and proportion of saccular space, indicates that animals in the Combined groups had very high growth rates of $\mathrm{EH}$ development both in the cochlea and in the saccule, regardless of the survival time between surgery and the measurement. Taking these results into consideration, the desmopressin-induced vestibular disorders in animals in the V-Combined-1 $\mathrm{W}$ group are readily understandable.

Generally, EH is well known to exist in cases with a clinical diagnosis of Meniere's syndrome. Conversely, nearly onethird of the cases of idiopathic hydrops show no association with the classic symptoms of Meniere's syndrome. ${ }^{33}$ In addition, previous histopathological examinations have revealed that the contralateral ears of patients with unilateral Meniere's disease showed asymptomatic saccular hydrops in around $30 \%$ of patients. ${ }^{34,35}$ Recently, Kato et al ${ }^{36}$ reported that there was no significant association between the degree of EH and caloric responses, using MRI. Previous studies have suggested that not only static morphological hydrops but also dynamic changes of hydrops may be
Table 1 Presence or absence of spontaneous nystagmus in experimental animals

\begin{tabular}{lcc}
\hline & \multicolumn{2}{c}{ Spontaneous nystagmus } \\
\cline { 2 - 3 } & Positive (\%) & Negative (\%) \\
\hline V-Control group & 0 & 100 \\
V-Desmopressin group & 25 & 75 \\
V-Surgery-1 W group & 0 & 100 \\
V-Surgery-4 W group & 0 & 100 \\
V-Combined-1 W group & 100 & 0 \\
V-Combined-4 W group & 100 & 0
\end{tabular}

Table 2 Maximum slow-phase velocity in animals with spontaneous nystagmus

\begin{tabular}{lc}
\hline 1 Week after Surgery & MSPV \\
\hline Animal 1 & -3.71 \\
Animal 2 & $3.99 \rightarrow-1.09$ \\
Animal 3 & 14.7 \\
Animal 4 & 2.41 \\
& \\
4 Weeks after surgery & \\
Animal 5 & -5.08 \\
Animal 6 & $6.51 \rightarrow-6.8$ \\
Animal 7 & $5.59 \rightarrow-2.47$ \\
Animal 8 & -3.66
\end{tabular}

Abbreviation: MSPV, maximum slow-phase velocity $(\%)$.

Positive and negative values are nystagmus toward surgical (left) and non-surgical (right) ears, respectively. In animals 2, 6, and 7, spontaneous nystagmus switch from irritative to paralytic.

responsible for the symptoms of $\mathrm{MD}$, and further support the validity of our new animal model for MD.

Endolymph flow measurements show that endolymph does not flow along the cochlea and it is generally agreed that most of the potassium in endolymph is recycled between perilymph and endolymph..$^{37,38}$ When the ES is in a normal state, the secretion and absorption of endolymph are well balanced. Previous molecular biological studies revealed that AQP2 mRNA expression in the cochlea as well as in the ES was upregulated by systemic application of VP. ${ }^{39}$ Morphologically, the endolymphatic space was found to increase in response to systemic application of VP. ${ }^{13}$ Clinically, Takeda et $a l^{9}$ demonstrated evidence of elevated serum arginine VP levels in patients with MD. Hornibrool et $a l^{40}$ reported that there have not been abnormal plasma levels of arginine VP in patients of MD. The reasons for these controversial results might have been that because platelets 
present in plasma cause overestimation of plasma arginine VP and partly to avoid degradation of AVP activity resulting from its short half-life, ${ }^{41-43}$ it might be one of the most important reasons for the great differences in basal arginine VP concentrations observed in different laboratories. These previous experimental findings indicate that the water homeostasis of the inner ear fluid is partly regulated via the VP-AQP2 system. In this study, desmopressin (V2 agonist) was used to examine the V2 effect of VP, not the vasopressin type 1 (V1) effect, because the V1 receptor, although limited to mRNA, is also expressed in the inner ear. ${ }^{44,45}$

On the basis of previous and present investigations, and given that patients with $\mathrm{EH}$ alone do not suffer from vertigo, we assume that the pathogenesis of vertiginous attacks is as follows: activation of the VP-AQP2 system by the V2 effect may yield overproduction of endolymph, with an increase in the influx of water from the perilymph into the endolymph, which causes sudden changes in endolymphatic pressure. We speculate that under chronic endolymphatic dysfunction, it may reduce absorption of endolymph and chemical mechanisms can concomitantly cause Meniere's symptoms. Chemical factors include hydrostatic pressure alterations, it changes membrane permeability, causing inappropriate ion across the membrane barrier so as to incite sensory dendrites and lead to cochlear and vestibular symptoms. In our experiment, we can see a remarkable histopathological change in the cochlea and saccule, not in the utricle and semicircular canals. There remains some discussion about whether an endolymph-perilymph pressure gradient may cause these morphological variations. Previous studies have shown that $A Q P 2$ protein and/or mRNA are expressed in the inner ear of rats. ${ }^{19,39,46}$ Furthermore, the V2 receptor and/or its mRNA are found in the cochlea. ${ }^{16,18}$ These previous studies suggest that water homeostasis in the inner ear is partly regulated via the VP-AQP2 system. If AQP2 protein and/or mRNA was to be overexpressed in the stria vascularis or vestibular dark cells, the VP-AQP2 system may promote overproduction of endolymph. Therefore, the difference in AQP2 expression in the stria vascularis and the dark cells may cause morphological variations. Further study is needed to determine the mechanism of the VP-AQP2 system in the inner ear using this animal model to understand the relationship between VP and MD.

Supplementary Information accompanies the paper on the Laboratory Investigation website (http://www.laboratoryinvestigation.org)

\section{DISCLOSURE/CONFLICT OF INTEREST}

The authors declare no conflict of interest.

1. Yamakawa K. Uber die pathologische Veranderung bei einem Meniere-Kranken. J Otorhinolaryngol Soc Jpn 1938;44:2310-2312.

2. Hallpike CS, Cairns H. Observations on the pathology of Meniere's syndrome. J Laryngol Otol 1938;53:625-655.
3. Kimura RS, Schuknecht H. Membranous hydrops in the inner ear of the guinea pig after the obliteration of the endolymphatic sac. Pract Otorhinolaryngol 1965;27:343-354.

4. Manni JJ, Kuijpers W, Huygen PLM, et al. Cochlear and vestibular functions of the rat after obliteration of the endolymphatic sac. Hear Res 1988;36:139-152.

5. Kakigi A, Taguchi T, Takeda T, et al. Time course of vestibular function changes of experimental endolymphatic hydrops in guinea pigs. ORL 2010;71(Suppl 1):19-25.

6. Andrews JC, Honrubia V. Vestibular function in experimental endolymphatic hydrops. Laryngoscope 1988;98:479-485.

7. Agre P, Sasaki S, Chrispeels MJ. Aquaporins: a family of water channel proteins. Am J Physiol Renal Physiol 1993;265:F461.

8. Nielsen S, Fronkiare J, Marples D, et al. Aquaporins in the kidney: from molecules to medicine. Physiol Rev 2002;82:205-244.

9. Takeda $T$, Kakigi $A$, Saito $H$. Antidiuretic hormone (ADH) and endolymphatic hydrops. Acta Otolaryngol Stockh 1995;519: 219-222.

10. Aoki M, Ando K, Kuze B, et al. The association of antidiuretic hormone levels with an attack of Ménière's disease. Clin Otolaryngol 2005;30:521-525.

11. Takeda T, Takeda S, Kakigi A, et al. Hormonal aspects of Ménière's disease on the basis of clinical and experimental studies. ORL 2009;71(Suppl 1):1-9.

12. Kumagami $\mathrm{H}$, Lowewenheim $\mathrm{H}$, Beitz $\mathrm{E}$, et al. The effect of anti-diuretic hormone on the endolymphatic sac of the inner ear. Pflugers Arch 1998;436:970-975.

13. Takeda T, Takeda S, Kitano $\mathrm{H}$, et al. Endolymphatic hydrops induced by chronic administration of vasopressin. Hear Res 2000; 140:1-6.

14. Kitano H, Takeda T, Takeda S, et al. Endolymphatic hydrops by administration of vasopressin in the rat. Acta Histochem Cytochem 2001;34: 229-233.

15. Kitano $H$, Takeda $T$, Suzuki $M$, et al. Vasopressin and oxytocin receptor mRNAs are expressed in the rat inner ear. NeuroReport 1997;8: 2289-2292.

16. Taguchi D, Takeda T, Kakigi A, et al. Expressions of aquaporin-2, vasopressin type 2 receptor, transient receptor potential channel vanilloid (TRPV)1, and TRPV4 in the human endolymphatic sac. Laryngoscope 2007;117:695-698.

17. Nishimura M, Kakigi A, Takeda T, et al. Expression of aquaporins, vasopressin type 2 receptor, and $\mathrm{Na}^{+}\left(\mathrm{KK}^{+}()^{-}\right.$cotransporters in the rat endolymphatic sac. Acta Otolaryngol 2009;129:812-818.

18. Nishioka R, Takeda T, Kakigi A, et al. Expression of aquaporins and vasopressin type 2 receptor in the stria vascularis of the cochlea. Hear Res 2010;260:11-19.

19. Kitano H, Suzuki M, Kitanishi T, et al. Regulation of inner ear fluid in the rat by vasopressin. NeuroReport 1999;10:1205-1207.

20. Dunnebier EA, Segenhout JM, Wit HP, et al. Two-phase endolymphatic hydrops: a new dynamic guinea pig model. Acta Otolaryngol 1997;117:13-19.

21. Lee KS, Kimura RS. Ischemia of the endolymphatic sac. Acta Otolaryngol (Stockh) 1992;112:658-666.

22. Takeda T, Kakigi A, Saito H. Epidural electrocauterization of endolymphatic sac. Equilibrium Res 1993;9(Suppl):139-143.

23. Okuno T, Sando I. Localization, frequency and severity of endolymphatic hydrops and the payhology of the labyrinthine membrane in Meniere's disease. Ann Otol Rhinol Laryngol 1987;96:438-445.

24. Nakashima T, Naganawa S, Sugiura M, et al. Visualization of endolymphatic hydrops in patients with Meniere's disease. Laryngoscope 2007; 117:415-420.

25. Fiorino F, Pizzini FB, Beltramello A, et al. Progression of endolymphatic hydrops in Ménière's disease as evaluated by magnetic resonance imaging. Otol Neurotol 2011;32:1152-1157.

26. Shambaugh GE, Clemis JD, Arenberg IK. Endolymphatic duct and sac in Meniere's disease. 1. Surgical and histopathologic observations. Arch Otolaryngol, 89:816-825.

27. Takeda T, Sawada S, Kakigi A, et al. Computed radiographic measurement of the dimensions of the vestibular aqueduct in Meniere's disease. Acta Otolaryngol (Stockh) 1997;528(Suppl): 80-84.

28. Sando I, Ikeda M. The vestibular aqueduct in patients with Meniere's disease. Acta Otolaryngol (Stockh) 1984;97:558-570. 
29. Egami T, Sando I, Black FO. Hypoplasia of the vestibular aqueduct and endolymphatic sac in endolymphatic hydrops. ORL 1978;86:327-339.

30. Kusakari J, Kobayashi $\mathrm{T}$, Arakawa $\mathrm{E}_{\text {, et }}$ al. Time-realted changes in cochlear potentials in guinea pigs with experimentally induced endolymphatic hydrops. Acta Oto-Laryngol Suppl 1987;435:27-33.

31. Kitahara M, Takeda T, Yazawa Y, et al. Experimental study on Meniere's disease. Otolaryngol Head Neck Surg 1982;90:470-481.

32. Nishimura M, Kakigi A, Takeda $T$, et al. Time course changes of vasopressin-induced enlargement of the rat intrastrial space and the effects of a vasopressin type 2 antagonist. Acta Oto-Laryngol 2009; 129:709-715.

33. Merchant SN, Adams JC, Nadol Jr JB. Pathophysiology of Meniere's syndrome: are symptoms caused by endolymphatic hydrops? Oto Neurotol, 2005;26:74-81.

34. Lin MY, Timmer FC, Oriel BS, et al. Vestibular evoked myogenic potentials (VEMP) can detect asymptomatic saccular hydrops. Laryngoscope 2006;116:987-992.

35. Morita N, Cureoglu S, Nomiya S, et al. Potential cause of positional vertigo in Ménière's disease. Otol Neurotol 2009;30:956-960.

36. Kato $M$, Teranishi $M$, Katayama $N$, et al. Association between endolymphatic hydrops as revealed by magnetic resonance imaging and caloric response. Otol Neurotol 2011;32:1480-1485.

37. Steel KP. Perspectives: biomedicine. The benefits of recycling. Science 1999:285:1363-1364
38. Sterkers $\mathrm{O}$, Ferrary $\mathrm{E}$, Amiel C. Production of inner ear fluids. Physiol Rev 1988;68:1083-1128.

39. Sawada $\mathrm{S}$, Takeda $\mathrm{T}$, Kitano $\mathrm{H}$, et al. Auaporin-2 regulation by vasopressin in the rat inner ear. NeuroReport 2002;13:1127-1129.

40. Hornibrool J, George P, Gourley J. Vasopressin in definite Meniere's disease with positive electrocochleographic findings. Acta Otolaryngol 2011;131:613-617.

41. Robertson GL, Mahr EA, Athar S, et al. The development and clinical application of a new radioimmunoassay for arginine-vasopressin in human plasma. J Clin Invest 1973;52:2340-2352.

42. Nussey SS, Ang VT, Bevan DH, et al. Human platelet arginine vasopressin. Clin Endocrinol 1986;24:427-433.

43. Bichet DG, Arthus MF, Barjon JN, et al. Human platelet fraction arginine-vasopressin. Potential physiological role. J Clin Invest 1987; 79:881-887.

44. Furuta $\mathrm{H}$, Luo $\mathrm{L}$, Ryan $A F$, et al. Expression of mRNA encoding vasopressin $\mathrm{V} 1 \mathrm{a}$, vasopressin $\mathrm{V} 2$, and ANP-B receptors in the rat cochlea. Hear Res 1998;117:140-148.

45. Furuta $\mathrm{H}$, Sato $\mathrm{C}$, Kawaguchi $\mathrm{Y}$, et al. Expression of mRNAs encoding hormone receptors in the endolymphatic sac of the rat. Acta Otolaryngol 1999;119:53-57.

46. Fukushima K, Takeda T, Kakigi A, et al. Effects of lithium on endolymph homeostasis and experimentally induced endolymphatic hydrops. ORL 2005;67:282-288. 